\title{
ALLEGORY IN LITERATURE AND LIFE
}

\begin{abstract}
Allegory is one of the distinguishing marks of many great works of literature. Over many centuries and cultures, authors have conveyed many symbolic messages about human life and the quest for religious faith in terms of different earthly trials and tribulations. These allegorical messages are closely linked, nonetheless, with many embodied conceptual metaphors that motivate different contemporary modes of thinking and language (e.g., LIFE IS A JOURNEY). My argument in this article is that literary allegory also has an important connection to our fundamental "allegorical impulse", in which humans automatically seek connections between the physical here and now with larger symbolic life themes. Allegory is a way we live, and seek meaning within our daily lives, that frequently gets elaborated upon in great works of literature.
\end{abstract}

Key words: allegory, allegorical literature, embodied conceptual metaphors, embodied simulation, allegorical impulse

\section{Introduction}

The literary term "allegory" comes from the Latin word "allegoria" indicating "veiled language", referring to discourse that conveys meaning which is hidden or beneath the overt understanding of the words presented. Allegories have been traditionally viewed as literary devices that convey (semi-)hidden or complex meanings through symbolic figures, actions, imagery, or events, which together express moral, spiritual, or political messages. Most allegorical messages are expressed through extended metaphors in which an entire narrative introduces and elaborates upon a metaphorical source domain (e.g., a specific physical journey) to evoke symbolic life themes (e.g., how to live one's life).

Some classic examples of allegory in literature include Aesop's Fables, in which Aesop used animals and their actions to allegorically represent human beings and their distinctive ways of living. ${ }^{1}$ Dante's Divine Comedy describes his journey through Hell, Heaven, and Purgatory to represent the journey of one's soul toward God (Alighieri 2007). The Faerie Queene by Edmund Spencer follows the lives of several knights as a means to examine different human virtues. Many readers interpret The Faerie Queene as an extended allegory written in praise of Elizabeth I, Queen of

\footnotetext{
" Cognitive Scientist, former Distinguish Professor of Psychology, University of California, Santa Cruz; e-mail: raymondwgibbs@gmail.com

${ }^{1}$ https://www.umass.edu/aesop/fables.php
} 
Raymond W. Gibbs, Jr.

England (Spencer 1979). Spencer even acknowledged that his book was "Cloudily enwrapped in Allegorical devices". John Bunyan's The Pilgrim's Progress describes a dream sequence in which a narrator talks of his personal journey from his hometown, the "City of Destruction" ("this world") to the "Celestial City", or Heaven, atop Mount Zion (Bunyan 2003). Bunyan's characters (e.g., Ignorance, Talkative, Pliable, Prudence, Discretion, etc.) were used to explain specific points about the practice and faith of the Protestant religion. George Orwell's Animal Farm portrays a farm governed by animals in which their thoughts and actions were intended to represent the communist regime of Stalin in Russia before the Second World War (Orwell 1996). Finally, William Golding's novel Lord of the Flies tells the story of a group of English schoolboys stranded on an island to raise questions about the rational mind, democracy, order and civility, and many other abstract ideals (Golding 2003).

These famous literary examples are only representative of an extensive body of works showing the allegorical mind in action. Although allegory is often thought to arise in specific cultural contexts and historical time periods, and certainly appeared to flourish in the Middle Ages (Brijak, in press), allegorical literature is commonly found throughout both history and cultural epochs. My argument in this article, however, is that allegory is not just a specific art form, or characteristic of only very special literary minds. Allegory is actually ubiquitous throughout everyday life whenever people connect their ordinary actions to larger symbolic themes about our humanly existence on earth and our spiritual lives after death. More specifically, allegory in its concrete manifestations in literature and art, as well as in ordinary life, emerges from a fundamental human disposition called "The Allegorical Impulse" (Gibbs 2011: 124):

Allegory is a fundamental property of human cognition in which we continually seek diverse connections between the immediate here and now with more abstract, enduring symbolic themes. The evocation of these symbolic themes creates rich, diverse networks of meaning that are metaphoric, deeply embodied, and give rise to multiple affective and aesthetic reactions.

Let's now examine the various ways that the allegorical impulse shapes the creation and interpretation of allegorical literature and then consider how allegory is a fundamental cognitive process that influences many aspects of everyday human life.

\section{Allegorical meanings in literary language}

Famous works of allegorical literature show how human minds from many cultures are capable of thinking about larger, existential life themes through the depiction of people in both mundane and extraordinary circumstances. A major 
focus of literary allegory is with human journeys in which people strive, and often struggle, to reach certain physical locations that are symbolically representative of abstract, sometimes religious or spiritual, ideas (e.g., Dante's journey toward God). This observation provides a first important clue to the psychological motivations for allegory. Whenever people face different life circumstances (e.g., young boys being stranded on a deserted island), metaphorical thinking bursts forth. Metaphor is critical whenever we face difficult to understand situations and enables us to make sense of abstract life events and concepts in more concrete terms (Gibbs 1994; Lakoff and Johnson 1980). A big part of what is most familiar to us, and helps us understand abstract concepts, is the human body, which serves as a critical source domain in many metaphors of thought, or conceptual metaphors. These conceptual metaphors provide a fundamental grounding for allegorical thinking and literature. For example, consider the following short list of conventional expressions:

Greta is making good progress toward her Ph.D. degree.

John has already reached several career goals.

David ran into a rough patch trying to solve the difficult math problem.

Sandra was completely stuck figuring out what to do after her divorce.

Lakoff and Johnson $(1980,1999)$ argued that these expressions are conventional manifestations of an underlying metaphor in thought, namely the LIFE IS A JOURNEY conceptual metaphor. The schematic phrase LIFE IS A JOURNEY represents only a convenient summary description of the rich set of mental mappings that characterize the complex relationship between the target (LIFE) and source (JOURNEY) domains. The LIFE IS A JOURNEY conceptual metaphor gives rise to a diverse set of mappings, which includes, at the very least, the following source-to-target domain correspondences (Kövecses 2010).

travelers $\rightarrow$ people leading a life

motion along the way $\rightarrow$ leading a life

destination(s) $\rightarrow$ purpose(s) of life

different paths to one's destination(s) $\rightarrow$ different means of achieving one's purpose(s)

distance covered along the way $\rightarrow$ progress made in life

locations along the way $\rightarrow$ stages in life

guides along the way $\rightarrow$ helpers or counselors in life 
Raymond W. Gibbs, Jr.

These correspondences are not simply a list of the features in common between LIFE and JOURNEY, precisely because conceptual metaphors help establish a more structured conceptualization of a target domain, which people then speak of using mostly conventional words and phrases. Many of us may think of the expressions listed above as being "dead" metaphors, but they are not. Psychological experiments indicate that ordinary people, and not just linguistic or literary scholars, interpret idioms and conventional metaphors (e.g., "John has already reached several career goals") via cross-domain mappings, showing that there are enduring links between conventional metaphorical meanings and vitally alive metaphorical thinking (Gibbs 1994, 2017). Both children and adults, speaking various languages, living in different cultures, at many historical times, think of their lives in conceptual metaphorical ways.

Notice another interesting aspect of the linguistic expressions listed earlier. These all refer to an abstract idea (i.e., thinking about one's life) in terms of concrete bodily actions (i.e., those related to our physical experiences of journeys). Not only are these statements reflections of metaphorical thinking, they also show the degree to which many facets of abstract thought are rooted in embodied experience. One of the major advances in cognitive science in recent decades is the recognition of how ordinary cognition is embodied. Our reasoning, imagining, perceptual and memorial abilities are mostly related to different recurring patterns of bodily actions and sensations (Gibbs 2006). This research adds evidence to support the proposition that human minds are not disembodied but emerge from, and continue to function in relation to, embodied activity.

Writers and poets often express broader, allegorical, ideas through concrete examples of embodied conceptual metaphors. A famous example of this is seen in a well-known work by the American poet Robert Frost (1969) titled "The Road Not Taken".

Two roads diverged in a yellow wood,

And sorry I could not travel both

And be one traveller, long I stood

And looked down one as far as I could

To where it bent in the undergrowth;

Then took the other, as just as fair, And having perhaps the better claim, Because it was grassy and wanted wear; Though as for that, the passing there Had worn them really about the same, 
And both that morning equally lay

In leaves no step had trodden black.

Oh, I kept the first for another day!

Yet knowing how way leads on to way,

I doubted if I should ever come back.

I shall be telling this with a sigh

Somewhere ages and ages hence;

Two roads diverged in a wood, and I-

I took the one less traveled by,

And that has made all the difference.

Most people recognize that this poem is not, just superficially, about a person walking through the woods, but expresses symbolic meaning about the choices we make over the course of our lives. Contemporary university students, who were not literature majors, were asked to write out their interpretations of the poem (Gibbs and Boers 2005). More than $80 \%$ of the students suggested that the poem had allegorical meaning. For example, as one student wrote, when asked to explain different parts of the poem:

This part of the poem is dealing with the choices we have to make in life. The two roads represent different pathways in life that one may or may not choose to take. Frost is saying that as a singular entity, you may only have a singular history which is comprised of the choices you have made. Different choices, or trying to clear a new road between the two existing ones (indecision) would result in a new person. The last line deals with the hesitancy to make a life changing decision. Options must be weighed carefully.

One does not have to be a literary expert to infer symbolic meanings regarding bodily actions given our bred-in-the-bone impulse to think and act in allegorical ways. In this case, students relied on their own bodily experiences of journeys to help them understand allegorical meaning in the poem.

The universal character of certain allegorical themes in literature is evident when looking at poetry and literature from different cultural contexts. Consider the following poem, titled "Two Roads," by the Serbian poet Miodrag Pavlovic (Pavlovic 2014): 
Raymond W. Gibbs, Jr.

One is a good road

and lit

much traveled

by wild animals

a tree

crags the eaves

On the other road

through a thicket

something snarls

a foul odor

withered leaf

and thorns

Along this road

which others shun

you set out to see

what the evil is.

This poem is also rooted in the embodied conceptual metaphor LIFE IS A JOURNEY. Although this conceptual metaphor is widespread, "Two Roads" is not merely another manifestation of the journey metaphor because readers fill in critical details given both their own understandings of journeys and their particular cultural knowledge related to the time and place in which the poem was first written. Thus, very specific allegorical meanings may be inferred, especially for readers with knowledge of Yugoslavian history and culture, which may give rise to particular political messages or meanings. Allegorical literature may emerge from embodied metaphorical concepts, but is always shaped by local historical, cultural and political circumstances, which give allegory very specific ways of expressing symbolic messages.

Allegory often imparts important life lessons, which is one reason why communities will spend so much time focusing on allegorical tales, as seen, for example in the Bible (within Parables and other parts as well). One of the most famous allegories related to LIFE IS A JOURNEY is in the Bible's Psalm 23 which overtly describes the physical journey through Egypt but alludes to the larger symbolic issue of humans striving to attain communion with the Lord:

The Lord is my shepherd; I shall not be in want. He makes me lie down in green pastures, he leads me beside quiet waters, he restores my soul. He guides me in paths of righteousness for his name's sake. Even though I walk through the valley of the shadow of death (i.e., Egypt), I will fear no 
evil, for you are with me; your rod and your staff, they comfort me. You prepare a table before me in the presence of my enemies. You anoint my head with oil; my cup overflows. Surely goodness and love will follow me all the days of my life, and I will dwell in the house of the Lord forever.

The reference to the Lord as a "shepherd" who "makes me lie down in green pastures ... [and] leads me beside quiet waters" and, later on, "prepare[s] a table before me in the presence of my enemies" alludes to larger symbolic themes about how the Lord offers guidance and safety through worship of his teachings. Notice how Psalm 23 is a specific manifestation of several of the entailments which arise from the mapping of journeys onto life (e.g., guides along the journey are counselors). The evocation of these symbolic themes, which are celebrated through public recitation of Psalm 23 in Christian church services, creates diverse, rich networks of meaning that are metaphorical, deeply embodied, and evocative of multiple affective and aesthetic reactions.

Are ordinary readers, who are not literary critics, able to infer complex allegorical messages from literature? Early work suggests that readers are quite capable of understanding relative simply allegories, such as that seen in Frost's "The Road Not Taken" (Gibbs and Boers 2005). A different empirical study further examined people's understanding and appreciating somewhat more complex segment of allegorical literature (Gibbs and Blackwell 2012). In The Anthologist by Nicolson Baker (Baker 2009), a poet who is editing a large volume of recent American poetry for a publisher is simply unable to write the introductory essay because he suffers from a terrible case of "writer's block", some of which is due to career and marital problems he had recently experienced. Toward the end of the novel, the poet/editor summarizes his dilemma in the following manner:

I wish I could spill forth the wisdom of twenty years of reading and writing poetry. But I am not sure I can.... Now it's like I'm on some infinitely tall ladder. You know the way that old aluminum ladders have the texture, that kind of not too appealing roughness of texture, and that kind of cold gray color? I'm clinging to this telescoping ladder that leads up into the blinding blue. The world is somewhere very far below. I don't know how I got here. It's a mystery. When I look up I see people climbing rung by rung. I see Jorie Graham. I see Billy Collins. I see Ted Kooser. They're all clinging to the ladder too. And above them, I see Auden, Kunitz. Whoa, way up there. Samuel Daniel, Sara Teasdale, Herrick. Tiny figures clambering, climbing.

The wind comes over, whsssew, and it's cold, and the ladder vibrates, and I feel very exposed and high up. Off to one side there's Helen Vendler, 
Raymond W. Gibbs, Jr.

in her trusty dirigible, filming our ascent. And I look down and there are many people behind me. They're hurrying up to where I am. They're twenty-three-year old energetic climbing creatures in their anoraks and goggles, and I'm trying to keep climbing. But my hands are cold and going numb. My arms are tired to tremblement. It's freezing, and it's lonely, and there's nobody to talk to. And what if I just let go? What if I just loosened my grip, and fell to one side, and just - ffffshhhooooww. Would that be such a bad thing? (Baker 2009: 267).

Fully understanding the text requires readers to engage in an extended metaphorical comparison in which the poet imagines his present obstacle "like" he was in the unworldly situation of clinging to an "infinitely tall ladder" which telescopes "up into the blinding blue." Participants in the Gibbs and Blackwell (2012) study gave various evidence of this embodied understanding through their responses to different questions about what they read.

Almost all participants recognized that the "infinitely tall ladder" was symbolic of the LIFE IS A JOURNEY conceptual metaphor by noting specific aspects of the mapping of journeys onto life, as when they observed how a journey consisted of a source (i.e., the beginning or lower parts of the ladder), a path (i.e., the ladder itself), and a goal (i.e., success, fame, the solution to the problem of writing the introductory essay). These references are often linked to specific bodily actions related to the poets climbing the ladder. The participants acknowledged, for instance, that the ladder represented the journey toward success such that poets higher up on the ladder were older and more famous, with those on the lower parts being younger and less famous. Moreover, almost all of the participants' responses alluded to the poet's clinging to the ladder as evidence of insecurity over what he was doing as a poet/editor and his potential for ever achieving fame as a poet. Thus, the poet being stuck on the ladder referred to something larger than just his being unable to make progress in physically climbing the ladder. The students also interpreted the poet's remarks that he should "loosen his grip" while on the ladder and "fall to one side" as implying that he wanted to give up trying to be successful and stop trying to write the introductory essay. Some participants felt that the poet's thoughts about loosening his grip and falling aside reflected his desire to get a different perspective on trying to write his introductory essay, or that he even wanted someone else to take over the project.

At the same time, the participants did not simply make sense of the passage through activation of the general conceptual metaphor of LIFE IS A JOURNEY and only report its typical entailments (i.e., the ladder is the path, the poets are travelers, the top of the ladder is the goal, etc.). Instead, people offered idiosyncratic interpretations of the story parts, giving their meaning products a unique character that speaks to 
everyone's individual, embodied, allegorical experience. For example, when asked about the meaning of "infinitely tall ladder," participants responded as follows: "The function of the ladder is to lead people into the imagination of poetry" and "The ladder provides the link between the realistic, mechanical world and the artistic world."

Most interestingly, these different meaning products are often linked to specific bodily actions related to the various poets climbing the ladder. All participants reported having various bodily experiences while reading the passage. Many referred to concrete physical sensations (e.g., feeling cold, tired, stomach sinking), while others noted more general psychological ills (e.g., anxiety, a sense of failure, a fear of competition). These sensations emerged during the actual reading of the story, as noted by some participants, and were not after-the-fact reflections on some preliminary, purely linguistic understanding of the text.

Not all literary allegories are extended metaphors that fully structure the meaning of some text, as is the case for Frost's "The Road Not Taken" and Baker's passage in The Anthologist. In many cases, allegories arise in shortened forms in what may be called "mini-allegories" (Gibbs, Okonski and Hatfield 2013). Consider one of the great poems in Middle English, Piers Plowman, written by William Langland. The poem, which is over 3000 lines long, is filled with metaphorical ideas and events within its description of many mundane human events and is widely heralded for its complex allegory and satire.

Personification is one method Langland frequently employs to make many complex allegorical points. Several inanimate nouns, such as "truth," "lie," and "money," are transformed into animate nouns, namely people, such as "Trueth," "Lyer," and "Mead," as seen in the conventional metaphorical expression "Truth has shaken off his chain." These personifications underlie different human events in the poem that sometimes present a clash between what the poem literally describes and some emergent abstract theme.

Most allegories operate by referring to concrete human events to comment on abstract human themes, especially those related to existential and spiritual struggles. But Piers Plowman, quite remarkably, also illustrates how allegory is bi-directional in showing how the concrete, mundane aspects of human life are themselves full of allegorical significance. For example, in one part of the poem, Piers Plowman appears, offers his guidance to penitents who are in the search for Truethe, but announces that he will not set off for this journey until he first plows and sows his half-acre of land. He asks the penitents to assist him in this task. But the day's work extends to many months and Plowman then speaks of the plowing of the field and the pilgrimage (seeking Truethe) as if they were one and the same: ${ }^{2}$

\footnotetext{
${ }^{2}$ http://sites.fas.harvard.edu/ chaucer/special/authors/langland/pp-pass6.html
} 
Raymond W. Gibbs, Jr.

"I wol worshipe Perwip truPe by my lyue,

And ben his pilgrym atte plow for pouere mennes sake." (6.101-2).

("I will worship therewith Truth, while I live,

And be his pilgrim at plow for all poor men's sake.”)

This linking of the field plowing with the pilgrimage is picked up again later on when Plowman receives a pardon as if he had actually made the real journey toward Trueth: ${ }^{3}$

"Treube herde telle herof, and to Piers sente

To [t]aken his teme and tilien Pe erPe,

And purchaced hym a pardoun a pena \& a culpa

For hym and for hise heires eueremoore after.

And bad hym holde hym at home and erien hise leyes,

And alle Pat holpen to erye or to sowe,

Or any [maner] mestier Pat myzte Piers [helpe],

Pardon wip Piers Plowman truPe haP ygraunted." (7.1-8)

("TRUTH hereof heard tell · and to Piers he sent,

To take him his team $\cdot$ and to till the earth;

And provided a pardon $\cdot$ a poena et a culpa

For him, and for his heirs: for evermore after.

And bade him hold him at home $\cdot$ and plow up his fields,

And all that helped him to plow $\cdot$ to set or to sow,

Or any other work $\cdot$ that might Piers avail,

Pardon with Piers Plowman - Truth them hath granted").

The allegorical meaning here is somewhat complex. Plowman clearly believes that going on a pilgrimage metaphorically represents the general search for Trueth, both as a concrete and as an abstract idea (i.e., Truth). Of course, the idea of LIFE IS A JOURNEY, and its more specific instantiation of FINDING THE TRUTH IS GOING ON A JOURNEY TO A SPECIFIC DESTINATION, are common metaphorical themes in many forms of allegorical literature (e.g., Pilgrim's Progress, Dante's Inferno). In this case, however, Plowman conveys a more specific instantiation of the FINDING THE TRUTH IS GOING ON A JOURNEY TO A SPECIFIC DESTINATION idea by suggesting that plowing itself represents the pilgrimage, or "the life of honest labour is a road to Trueth" (Mann 1991: 28). However, the metaphor at work here is not just that of plowing as a pilgrimage, but something far richer and more deeply experiential. The entire act of plowing, where

\footnotetext{
${ }^{3}$ http://sites.fas.harvard.edu/ chaucer/special/authors/langland/pp-pass7.html
} 
one begins on one part of an unturned field and works slowly, often with great difficulty, to transform the soil in order to sow it, suggests that the activity of plowing is its own sort of pilgrimage in various metaphorical ways. For example, progress in the act of plowing a field is mapped onto progress in the pilgrimage. Obstacles encountered during plowing are obstacles encountered over the course of a pilgrimage. Removing, or overcoming, obstacles when plowing corresponds to overcoming obstacles along the pilgrimage journey. Arrival at a desired destination, or when one comes to the end of plowing a field, corresponds to coming to the end of a pilgrimage and experiencing a spiritual awakening. Finally, the failure to overcome obstacles when plowing, the failure to reach the end of one's plowing task, also relates to failure in the progress and success of the pilgrimage.

Langland created a distinctive allegory that departs from most other medieval allegories in which a material object is used to refer to, and better understand, abstract, sometimes spiritual, ideas and aspirations. In this manner, allegory is not completely separate from physical actions because literal meaning is often immediately evocative of metaphorical and allegorical understandings.

In fact, common linguistic expressions regarding bodily actions also immediately convey metaphorical messages. Consider the following English idiomatic expressions:

\author{
go out on a limb \\ skating on thin ice \\ rock the boat \\ spill the beans \\ get away with murder
}

When these phrases are used in literal, physical contexts, they automatically evoke their figurative, metaphorical meanings. When one "goes out on a limb", one is metaphorically also in a precarious, potentially dangerous situation. The same idea applies to literal uses of "skating on thin ice" and "rock the boat." When one literally "spills the beans", that person is also metaphorically expressing the idea that some materials are now suddenly revealed for all to see. And when one literally commits murder, and gets away with this crime, one metaphorically has engaged in a terrible action and has not had to suffer any penalty for doing so.

Many proverbial expressions also convey metaphorical ideas when employed in purely literal circumstances. For example, the suggestion "don't count your chickens before they are hatched", in the context of chicken hatching immediately conveys the broader symbolic message of not prematurely doing something before some precondition has been met. Similarly, "the early bird captures the worm" when used literally in talking about early morning bird behavior immediately evokes the message 
Raymond W. Gibbs, Jr.

that getting a head-start in one's daily activities is likely to lead to greater success than if one delays.

Experimental studies show that people quickly infer metaphorical meanings when they hear idioms and proverbs being used literally (Gibbs 1980, 1986). This general finding is not simply due to a tight, yet arbitrary, association between the literal and metaphorical meanings of many idioms and proverbs. Instead, understanding the literal bodily actions referred to in many idioms and proverbs immediately leads people to infer broader symbolic meanings regarding these actions.

Much allegorical literature conveys complex resonances between the literal, physical world of mundane human behaviors and larger symbolic, allegorical themes. This confluence between the physical and the allegorical highlights the intimate connection between allegory in everyday life and great works of allegorical literature.

\section{Embodied imagination in allegorical thinking}

Allegorical thinking is rooted in our embodied imaginative capabilities. One of the important developments in cognitive science that has direct application to understanding allegory in literature and life is the idea that people interpret language not simply through the decoding of linguistic symbols (e.g., words, sentences, narratives), but via an embodied simulation process in which they imagine themselves engaging in the thoughts, feelings and actions of others, as depicted in language (Bergen 2012; Gibbs 2006, 2017). For example, readers interpret Frost's poem and the allegorical story in The Anthologist by imaginatively projecting themselves into the actions within the story world (e.g., walking through the woods and having to decide which of two roads to follow). This claim has its origins in cognitive neuroscience studies on "mirror neurons", which show with both humans and non-human primates that motor areas of the brain are activated when individuals see other actors performing different bodily motions (Gallese 2005). These findings imply that people tacitly imagine themselves performing the actions they perceive, which enables them to understand through simulations what other individuals are doing, as well as perhaps thinking and feeling.

Somewhat surprisingly, embodied simulations are also involved when people interpret language that is abstract or metaphorical. The simple statement "John couldn't grasp the concept of infinity" is impossible to perform in the real world, yet we simulate this action by imagining the "concept" to be a concrete object that can be understood once physically grasped (Wilson and Gibbs 2007). Similarly, people may have climbed a ladder leading up into the blinding blue, but their experiences of climbing and being in precarious physical situations, enable them to create simulations 
of what they read in the allegorical take within The Anthologist. The automatic power of embodied simulation processes is such that readers are often unable to resist drawing allegorical interpretations of a poem even when they are instructed to pay attention only to the literal, surface meanings of texts (Okonski and Gibbs 2019). More generally, embodied simulation processes likely exist along a continuum of depth starting with shallow processing where there is little embodied involvement in language understanding, moving up to a middle ground where mostly unconscious recruitment of sensorimotor knowledge and experiences are active during language processing, up to rich imaginative bodily imagery which is quite consciously understood and felt (Gibbs 2017).

\section{Allegory in life}

Allegory is not just a literary phenomenon but emerges, somewhat spontaneously, in certain aspects of ordinary discourse, whenever people talk about challenging obstacles in their everyday lives. For example, consider part of a conversation between a psychotherapist, Judy, and her client, Howard (Ferrara 1994: 139-141). Howard, age 40 , had recently lost his job and was struggling to figure out how he wanted to proceed next in life.

Judy: "When you have a problem, what do you do with it?"

Howard: "I usually let it be a problem. I don't usually do anything much..."

Judy: "Does the problem go away if you don't do anything about it?"

Howard: "No, it get's worse.. or it just complicates things as you go further down the road."

Judy: "Can you look at your own life... look down the road of that line and see what that's gonna do.. in your life?"

Howard: "Look down the road?"

Judy: "Yeah, kinda visualize what your own life will be like...."

Howard: "It will just continue the way it is."

Judy: "Kind of like a snowball effect."

Howard: "No no not a snowball. Just kinda floating, floating down the river..."

Judy: "What's it like to be floating down the river? Tell me more."

Howard: "It's comfortable. It's safe.. Everything just keeps on an even keel, you know... You're just kinda floating."

Judy: "Kind of in a canoe? Going down the river or..."

Howard: "No, more like a great ole big barge.. on a great old big river."

Judy: "Barge, very stable, kinda."

Howard: "Yeah, plenty of room to spread out and sit in the sun. Yeah, and you don't have to worry about falling off the edge.. And sun, you know, 
Raymond W. Gibbs, Jr.

it's kinda hazy. It's not really clear sun. It's kinda hazy. Kinda half asleep, that's what it's like."

Judy: "What happens when you kind of come to the falls, the falls that are down there, about two miles down the river?"

Howard: "Get the hell off the river!"

Judy: "Last time there was um kind of an external situation that sort of forced you out of your boat."

Howard: "It was uncomfortable, but I was, I was pretty, I was enjoying it too. And I didn't want to go back into just floating. It was uncomfortable and I was out, I don't, I've been floating a long time."

Judy: "Mmm, well you've found what works for you, in a sense."

Howard: "What works for me?"

Judy: "Floating."

Howard: "Because I'm.. stay comfortable and"

Judy: "In a sense, but it may now be... inappropriate. It may not be working as well as it did in the past."

Howard: "Yeah, I need a little excitement now and then."

Judy: "Some rapids."

Howard: "Yeah, something I can keep in control of and not drown."

This conversation illustrates how Judy and Howard co-construct a metaphorical conception of his life as a journey, specifically as a journey on a barge floating down the river. Once again, metaphorical thinking and language bursts forth whenever people face difficulties in life, such as being ill, having emotional and relationship problems, or any circumstances requiring some adjustment to one's immediate and long-term situation. But the metaphorical theme that emerges in the conversation between Judy and Howard actually reflects allegorical thinking in action. Both patient and therapist explored the symbolic ramifications of Howard's understanding of his life as a specific type of journey, specifically in terms of whether it is still appropriate to continue viewing his life, indeed continue living his life, in this particular symbolic manner. As is the case with many therapies, both for physical and psychological disorders, the treatment is geared not to stripping away metaphorical, allegorical understandings of one's life and problems, but toward finding alternative metaphorical themes by which one can more productively experience life.

Allegorical thinking arises not only when people talk with one another, but also in surprising ways whenever each of us confronts real or imaginative obstacles in everyday life. I once privately experienced a powerful allegorical realization that has had a lasting influence on my life and career. After graduation from high school, I immediately got a job working on a truck delivering goods in and around Boston, 
Massachusetts. On the second day, the driver quit and I was given the position as driver, with no assistant, despite being underage and not having the proper driver's license needed to operate a large truck. Within 20 minutes on that first memorable day, I was trying to drive down this very narrow street in downtown Boston that had parked cars on both sides. I did not believe that my large truck was capable of making it through the parked cars and I felt panic. Not knowing what to do, and believing at first that I may be stuck, I quickly decided that I should simply look straight ahead and step on the gas. Sure enough, my truck moved forward and soon I was at the end of the street and out onto a bigger street. Feeling delighted at this little success, I quickly realized that there was a message to take from this small life experience: When in doubt, look straight ahead and step on the gas! Since that time, I have repeatedly remembered this lesson whenever I was confronting what appeared to be unrelenting obstacles, both physical and metaphorical. Don't worry about the problems surrounding you, just focus on the goal and continue to move forward without fear of failure.

The "move forward without fear in the face of obstacles" message is allegorical precisely because it draws a larger symbolic theme from an ordinary, typically physical, life experience (e.g., being stuck in a traffic jam). My automatic tendency to create larger symbolic, even poetic, meaning for mundane life experience reflects the "allegorical impulse" in action.

I have, quite selfishly, one other personal allegorical tale that is relevant here. In the last year, I have taken up an old, long-abandoned hobby of creating abstract paintings while sitting in my garage. Painting has always been a relaxing pursuit for me, but it is also one that fully engages my mind in fantastic non-verbal ways. One challenge I often face, though, is that I will be splashing paint around, hoping to create some pictorial effect, when something goes awry, as when some paint drips down the canvas, or some color combination suddenly turns to mud, and so on. The allegorical moment for me was that I have learned to make the best of my painting mistakes and try to reinvent what I was hoping to accomplish and now create something different. Mistakes are opportunities for improvement! This lesson is not only relevant to my painting, but to my life more generally. Whenever I commit some error, or something does not work out according to plan, I try to make the best of this event and create something different and usually much better for myself.

Allegorical lessons such as seen in my truck driving and painting stories are again, deeply tied to physical, bodily actions. Bodily actions, both real and imaginative, are themselves ripe with potential for allegorical thinking.

The allegorical impulse is not just a way of thinking that helps us interpret various past and present life moments or a mode of understanding the communicative, aesthetic intentions of others when reading certain literary works. More fundamentally, 
Raymond W. Gibbs, Jr.

allegory is something we actively seek out for ourselves in everyday life. Consider individuals who immerse themselves in arduous physical journeys.

Every year, many thousands of people attempt to walk the "Camino de Santiago", or "Pilgrimage of Compostela", a journey of nearly 500 miles, within France and Spain. One description of this pilgrimage is the following:

Because the pilgrim undertakes the route to the tomb of the Apostle, pursuing an encounter with his or her faith, but also as a search of the spirit or internal journey. In a society that drags you and beats you down, the Camino de Santiago allows you to stop and become aware of yourself. Reflection, friendship, solidarity, reflection, communion with nature or solitude are some of the sensations that allow every pilgrim to experience a spiritual connection. ${ }^{4}$

Although people setting out on this journey rarely think "I wish to discover allegory", they often consciously recognize the symbolic meanings of their immediate physical efforts, and will often, nonetheless, describe the journey as related to metaphor. As one walker noted, "The Camino, as a metaphor of life, allows you to divest yourself from everything, allows you to search for answers and helps in the awakening of consciousness, allowing you to look beyond your day to day." ${ }^{5}$

An individual need not undertake heroic, physically exhausting, sometimes dangerous, journeys to discover allegorical connections between the here-and-now with larger symbolic meanings. Even small, routine bodily habits can be evocative of allegory. Consider, for example, a retired high school art teacher, now in his late 70 s, who has a daily hobby of walking back and forth along a 14-foot long tight wire secured in his living room, suspended several feet above the ground (San Francisco Chronicle, June 2009, "Retired Teacher Finds Balance"). He commented on this daily obsession as follows:

It's all about balance. Basically, we are all walking a tight wire, and when you are on the wire, you have to be focused... So many things affect your balance. If you're tired, depressed, impetuous, unfocused, irritable, hungry, it shows up immediately on the wire.

When I first read the newspaper article about the retired teacher and his tightwire habit, it seemed as if the teacher spoke directly about my life too. Many moments in my life feel as if I am walking along some tight wire desperately trying to stay balanced, especially during those moments when I too feel tired, depressed, impetuous, unfocused, irritable, hungry and so on. Walking along a tight wire, where there is

\footnotetext{
${ }^{4} \mathrm{https} / /$ www.elcaminoconcorreos.com/en/blog/spirituality

${ }^{5}$ Ibid.
} 
always some danger of losing balance, and falling into a unknown chasm, beautifully captures the essential metaphorical idea of LIFE IS A JOURNEY, and gives this metaphor a precise allegorical realization that both makes sense and feels like how life is for me, and surely others. Engaging in even minor bodily challenges, such as walking along a tight wire, sets the stage for allegorical meaning to blossom.

\section{Conclusions}

Allegory is mostly studied as a literary device employed by brilliant writers and artists to convey symbolic messages by which we can better understand the challenges we face in our lives. Most allegories focus on major life themes, including our desires for salvation and redemption within our earthy experiences and spiritual after lives. Scientific studies reveal that ordinary people are quite capable of understanding both simple and complex allegorical tales, and can, in some circumstances, articulate the larger life lessons that great artworks indirectly express through allegory.

Experimental studies within cognitive science also reveal that our ability to readily infer allegorical meanings from language is grounded in automatic embodied simulation processes. We instinctively project ourselves into the language and actions of other people and from this come to understand something about what others are doing and why they do so. These simulation processes are not just a matter of creating a "theory of mind" for others, but involve us imaginatively engaging with our bodies in the same actions, and thinking the same thoughts and feelings of others. Our ability to understand allegory in literature is tied to these embodied simulations and our related abilities to see connections between the physical here-and-now and larger symbolic life themes (i.e., the allegorical impulse).

Our talent for interpreting allegorical meanings in literature, via embodied simulation processes, is tied to the automatic ways we find allegory in our own everyday, mundane, lives. Human bodily action is rarely untouched by symbolism, and we often stumble across allegorical meanings, especially when dealing with unexpected life challenges, both physical and psychological. But our impulse for allegory also leads us to seek out physical experiences that are evocative of allegorical messages. All human beings seek out allegory in one form or other. Life is almost meaningless without allegory.

Some traditional scholars may complain that my discussion of allegory too greatly expands upon the term "allegory", which should be described, more narrowly, as a very specific rhetorical form, or literary device. My argument is that there are obvious psychological reasons for why some individuals, across time and culture, create allegorical literature and artworks. These reasons are rooted in the poetics of 
Raymond W. Gibbs, Jr.

every life experience in which we often seek out meaningful relationships between the bodies physical actions and larger symbolic life themes. Allegory is something we live! My hope is that all readers of this article will take great joys in the multitude of allegories you encounter and seek to discover in everyday life. Allegory is freedom of the imagination so please enjoy all the allegories you live.

\section{References}

Alighieri, D. (2007). The Divine Comedy of Dante. New York: Forgotten Books. Baker, N. (2009). The Anthologist. New York: Simon \& Schuster.

Bergen, B. (2012). Louder than Words. New York: Basic Books.

Brijak, V. (ed.) (in press). Allegory Studies: Contemporary Perspectives. New York: Routledge.

Bunyan, J. (2013). Pilgrim's Progress. Mineola, New York: Dover.

Ferrara, K. (1994). Therapeutic Ways with Words. New York: Oxford.

Frost, R. (1969). The Poetry of Robert Frost. New York: Holt, Rinehart, and Winston. Gallese, V. (2005). Embodied Simulation: From Neurons to Phenomenal Experience. Phenomenology and the Cognitive Sciences, 4, 23-48.

Gibbs, R. (1986). Skating on Thin Ice: Literal Meaning and Understanding Idioms in Conversation. Discourse Processes, 7, 17-30.

Gibbs, R. (1994). Poetics of Mind: Figurative Thought, Language, and Understanding. Cambridge and New York: Cambridge University Press.

Gibbs, R. (2006). Embodiment and Cognitive Science. Cambridge and New York: Cambridge University Press.

Gibbs, R. (2011). The Allegorical Impulse. Metaphor and Symbol, 26:2, 121-130.

Gibbs, R. (2017). Metaphor Wars: Conceptual Metaphors in Human Life. Cambridge and New York: Cambridge University Press.

Gibbs, R. and N. Blackwell (2012). Climbing the Ladder to Literary Heaven: A Case Study of Allegorical Interpretation of Fiction. Scientific Study of Literature, 2, 199-217.

Gibbs, R. and E. Boers (2005). Metaphoric Processing of Allegorical Poetry. In: Z. Maalej (ed.), Metaphor and Culture, Tunisia: University of Manouba Press, 66-81.

Gibbs, R., L. Okonski and M. Hatfield (2013). Crazy, Creative metaphors: Crazy Metaphorical Minds? Metaphor and the Social World, 3, 141-159.

Golding, W. (2003). Lord of the Flies. London: Penguin. 
Kövecses, Z. (2010). Metaphor: A Practical Introduction. Oxford and New York: Oxford University Press.

Lakoff, G. and M. Johnson (1980). Metaphors We Live By. Chicago: University of Chicago Press.

Lakoff, G. and M. Johnson (1999). Philosophy in the Flesh. New York: Basic Books.

Mann, J. (1991). Langland and Allegory. In: D. Donoghue, J. Simpson and N. Watson (eds.), The Morton W. Bloomfield Lectures 1989-2005, Kalamazo, MI: Medieval Institute Publications, 20-41.

Okonski, L. and R. Gibbs (2019). Diving into the Wreck: Can People Resist Allegorical Meaning? Journal of Pragmatics, 141, 28-43.

Orwell, G. (1996). Animal Farm. London: Penguin.

Pavlovic, M. (2014). Selected Poems. London: Cromer.

Spencer, E. (1979). The Faerie Queene. London: Penguin. 